\title{
Antecedentes y aproximación teórica sobre identidad territorial y desarrollo local en la zona norte de la ciudad de Tipitapa, Managua, Nicaragua
}

\author{
Samanta María Espinoza Rivera ${ }^{1}$
}

\section{RESUMEN}

El presente artículo surge de la necesidad de comenzar con la revisión documental relacionado con el tema de investigación "identidad territorial y desarrollo local en la zona norte de la ciudad de Tipitapa, municipio de Tipitapa, departamento de Managua 2017-2019”. Tiene como propósito identificar los estudios realizados, así como los planteamientos teóricos existentes sobre el tema en cuestión. Para la realización del escrito se auxilió de la técnica de la revisión bibliográfica y análisis documental. Se puede concluir, que para el estudio de la identidad territorial existen investigaciones que tratan el estudio de la identidad desde la comprensión del sentido de pertenencia que tiene una comunidad sobre la ocupación del espacio, su tierra, ambiente y recursos naturales. En definitiva, los rasgos de identidad con el territorio, se ven influenciado por la asociación entre las condiciones subjetivas y objetivas de los habitantes, es decir, la actitud que la población tiene del lugar está condicionada por las oportunidades de desarrollo o la estructura económica que prevalece en función del desarrollo territorial.

Palabras clave: antecedentes, aproximación teórica, identidad territorial, desarrollo local.

Recibido: 10 de mayo de 2017

Aceptado: 05 de septiembre de 2017

1 Docente de UNAN-Managua. Estudiante del Doctorado Gestión de la Calidad de la Investigación. UNAN-Managua FAREM-Estelí. Correo electrónico: samantamaria7@hotmail.com 


\title{
Background and theoretical approach on territorial identity and local development in the northern area of the city of Tipitapa, Managua, Nicaragua
}

\begin{abstract}
This article arises from the need to begin a the documentary review related to the research topic "territorial identity and local development in the northern area of the city of Tipitapa, municipality of Tipitapa, Department of Managua 2017-2019". Its purpose is to identify the studies carried out, as well as the existing theoretical approaches on the subject. For completion of this study it was assisted by the technique of the bibliographic review and documentary analysis. It can be concluded that for the study of territorial identity there are investigations that deal with the study of identity from the understanding of the sense of belonging that a community has about the land use, environment and natural resources. In summary, the features of identity with the territory, are influenced by the association between the subjective and objective conditions of the inhabitants, that is, the attitude that the population has of the place is conditioned by the development opportunities or the economic structure that prevails depending on territorial development.
\end{abstract}

Keywords: background, theoretical approach, territorial identity, local development. 


\section{INTRODUCCIÓN}

Para iniciar este artículo se hace referencia al significado del término "identidad territorial". Las interrogantes que se plantean son: ¿Qué es lo que localmente refleja la identidad del territorio?, ¿Tiene la identidad repercusiones en el ambiente y economía del territorio?, ¿Tienen todos los actores locales la misma percepción sobre la identidad del territorio?,¿Cuáles son los elementos que expresan la pertenencia a un territorio?

El estudio de la identidad territorial profundiza en los problemas comunales que influyen en el ambiente natural, así mismo considera la búsqueda de elementos de identidad con el territorio, que permitan articular el beneficio individual en función de una colectividad, desde el sentido de pertenencia, es decir, un estudio desde la perspectiva de la Geografía, para indagar en un marco teórico y metodológico que fundamente este enfoque.

Por otro lado, el estudio de identidad territorial traduce aspectos propios de poblaciones y territorios (muchos de ellos subjetivos), además que concentra esfuerzos para generar un conocimiento y apropiación real de los problemas y dar alternativas de solución a los mismos, en función del buen aprovechamiento de los recursos naturales.

A lo largo del tiempo, el ambiente ha sido objeto de estudio para distintas disciplinas científicas. En concreto, la Geografía considera el ambiente como un factor que contribuye a modelar las formas de vida y las relaciones humanas.

Por su parte, la Ecología investiga las interrelaciones entre las poblaciones y su medio. A su vez, la Historia plantea que los diferentes tipos de organización productiva condicionan la relación que las sociedades establecen con el ambiente. De esta forma, se reconoce que tanto los factores históricos como los elementos ecológicos -terreno, flora y fauna, clima y recursos naturales- configuran la cultura, que a su vez influye en el desarrollo de la personalidad (Triandis y Suh, 2002). Actualmente la crisis ecológica es una consecuencia de la degradación que los seres humanos provocan en los ecosistemas a través de prácticas productivas orientadas a cubrir las necesidades materiales y de supervivencia de la población.

Con la idea de progreso ilimitado y con el desarrollo tecnológico de los últimos siglos, el ser humano ha conseguido imponerse al ambiente para satisfacer necesidades de movilidad y crecimiento impuestas por una cultura sin desarrollo sostenible. Sin embargo, los conocimientos científicos muestran que los recursos no son ilimitados y que las prácticas agrícolas masivas, los hábitos de vida y de consumo están dañando gravemente los ecosistemas y poniendo en peligro el bienestar del ser humano. Puesto que una de los orígenes de los conflictos ambientales está relacionadas con el sentido de pertenencia hacia el territorio y sus recursos naturales, con la conducta humana; la solución podría hallarse en el fortalecimiento de la identidad territorial que influye en el cambio de la conducta de los grupos y de las organizaciones, en las conductas políticas del uso racional de los recursos y, por tanto, en cambios culturales y de estilos de vida. (Moraga, 2009)

¿Qué es identidad? Gonzáles (2000) citado por (Molano, 2006) señala que es "el sentido de pertenencia a una colectividad, a un sector social, a un grupo específico de referencia. Esta colectividad puede estar generalmente localizada geográficamente, pero no necesariamente (por ejemplo, los casos de refugiados, desplazados, migrantes, etc.). Hay manifestaciones culturales que expresan con mayor intensidad que otras su sentido de identidad, hecho que las diferencian de otras actividades que son parte común de la vida cotidiana" (pág. 6).

La identidad se concibe y estudia desde varios enfoques disciplinares, ciencias como la Antropología y la Geografía para citar algunas, conciben la identidad de distinta forma y le asocian el elemento particular como, 
por ejemplo, la antropología social la llama identidad cultural y Geografía la denomina identidad territorial. Desde el enfoque de la Antropología, la identidad está determinada por la cultura de un pueblo, enmarcada en su historia, costumbres, lengua, entre otros elementos. Molano O. (2006) expresa que "la identidad cultural de un pueblo viene definida históricamente a través de múltiples aspectos en los que se plasma su cultura, como la lengua, instrumento de comunicación entre los miembros de una comunidad, lasrelaciones sociales, ritos y ceremonias propias, o los comportamientos colectivos, esto es, los sistemas devalores y creencias."

Así mismo, la Geografía relaciona la identidad con el territorio, señalando que la identidad territorial se construye a partir de percepciones, apreciaciones y valoraciones del espacio habitado, que generan un sentido de pertenencia, que lo hacen especial (o único) para sus habitantes, a partir de lo cual van construyendo determinados modos de vida y estrategias que se manifiestan de diferentes formas en el territorio.

\section{MATERIALES Y MÉTODOS}

La investigación es no experimental, con respecto a este punto, Hernández, Fernández y Baptista (2003, p: 286-289) expresa que este tipo de estudio se realiza sin manipular deliberadamente las variables independientes, y se basa en categorías, conceptos, variables, sucesos, comunidades o contextos que ya ocurrieron, o se dieron sin la intervención directa del investigador. Para la recopilación de los datos se realizó la revisión bibliográfica, donde se hicieron consultas en libros, tesis, informes y artículos científicos relacionados con el tema de identidad territorial y desarrollo local en la zona norte de la ciudad de Tipitapa, municipio de Tipitapa, departamento de Managua 2017-2019.

Por otro lado, el análisis documental que según Gómez (2000:43), es una técnica que busca descubrir el significado de un mensaje, ya sea en un discurso, una historia de vida, un artículo de revista, etc. Esta consiste en clasificar y/o codificar los diversos elementos en categorías con el propósito de hacer aparecer de la mejor manera el sentido de la información. Es una técnica para la descripción objetiva y sistemática del contenido, teniendo como fin la interpretación del mismo. Para aplicar la técnica de análisis documental se diseñó un formato con los ejes de análisis, derivados de los objetivos de la investigación.

Los materiales que utilizaron son: fichas bibliográficas, guía del análisis documental contempla las fuentes escritas para analizar y los aspectos que interesan, así mismo computadora portátil y Word versión 2013.

\section{RESULTADOS Y DISCUSIÓN}

La identidad surge como resultado del proceso de desarrollo, en la medida en que cada comunidad, al evolucionar en el tiempo, va generando costumbres, leyes, productos que forman su cultura; y, a la vez, descubrimos que la cultura hace posible el desarrollo.

La identidad territorial, es un elemento determinante que encamina las decisiones de participación social, sobre todo, del sentido de pertenencia al lugar que se habita; la reversión de la segregación socioeconómica y un mejor aprovechamiento de los beneficios que brindan los territorios que ocupan; en tal sentido constituye un elemento clave para la formulación de propuestas encaminadas a democratizar la gestión del espacio habitable. En este sentido, existen estudios relacionados con la identidad territorial, tanto a nivel nacional e internacional. A continuación, se destacan los siguientes antecedentes:

El Grupo de Investigación $\mathrm{I}+\mathrm{C}$ de la Universidad de Murcia (2009) desarrollo un estudio que se titula "la identidad y conciencia regional en Murcia", cuya investigación hace referencia a que la identidad de los habitantes se valora a distintas escalas, a nivel individual, local, nacional y global. A nivel individual se plantean preguntas, tales como: ¿cuáles son los elementos que conforman la identidad que somos y 
qué papel desempeña en la relación que cada persona establece con sus conciudadanos; a nivel local se afrontan las tensiones y el aprendizaje cultural necesario para compartir las múltiples identidades que conforman los pueblos y ciudades; a nivel nacional se mantiene el problema que surgió de las exigencias de grupos que reclaman identidades colectivas propias; a nivel global se están consolidando nuevas identidades, tanto reales como virtuales, y se debate la cuestión de cómo establecer puentes de diálogo que permitan una verdadera convivencia de todas las culturas dentro de este mundo globalizado que nos ha tocado vivir.

Arellano (2007) realizó un estudio sobre la "identidad territorial como base del desarrollo local en el Secano Interior de San Javier de Loncomilla, Región del Maule. Estudio de caso de la sociedad campesina barrancas y Valle de Pichamán", que plantea una de las dimensiones fundamentales en el desarrollo del territorio es la dimensión social, cuya base articular es la identidad territorial de sus comunidades que buscan esta nueva forma de concebir y hacer desarrollo. En términos estratégicos, en las condiciones de competencia y producción es fundamental reforzar la importancia de la solidaridad y calidad de las redes, de los vínculos sociales y de identidad territorial en el seno de la economía, en vez de destruir o desestabilizar estas interacciones.

Del mismo modo, el estudio plantea que más allá de la subjetividad de los espacios locales como una pieza fundamental en las estrategias de desarrollo a nivel comunal o regional, esta se tiene que considerar como oportunidades de reforzamiento de la identidad territorial-cultural de sus habitantes, de rescate y manejo de los capitales intangibles de sus comunidades (capital cognitivo, simbólico, cultural, cívico, psicosocial, humano y sinergético) y de esta manera, alcanzar un desarrollo social firme y concordante, capaz de generar las directrices del desarrollo que los habitantes desean para sí mismos, quienes son capaces de formular sus propias estrategias convenientes a un desarrollo endógeno que no necesariamente se transforma en crecimiento, un desarrollo los habitantes sean partícipes y en donde sus propios intereses se verán reflejados.

Cabe señalar que la investigación anterior resalta la importancia de descubrir y potenciar el capital social de la comunidad territorial; despertando el interés de una colectividad que acepta el desafío de innovar, sin estar dispuesta a arriesgar o modificar de manera significativa sus modos de vida tradicionales y que el principal motivo de la participación en sociedad, no es sólo por conseguir recursos para potenciar el desarrollo económico-productivo, sino más bien, la idea de obtener y construir algo en conjunto, como grupo.

Orduna (2012) desarrolló un estudio sobre "Identidad e identidades: Potencialidades para la cohesión social y territorial", plantea que cuando las personas eligen afiliarse a la identidad común es porque reconocen en ella y tienen aportes positivos que realizar para la mejora de su comunidad. Se propician situaciones en las que el ser humano, a otros individuos, que intenta optimizar sus condiciones de vida, generando respuestas a sus necesidades y deseos, dando soluciones originales y creativas a problemas que su medio le plantea. Además, reafirma que los procesos de constitución de identidad se vuelven motores del desarrollo y tiene las siguientes características: 1 . Reúne el pasado, el presente y el proyecto en una única realidad interiorizada por el conjunto de los miembros de la sociedad. 2. Se desarrollan en una realidad cultural donde se valoran la innovación, el trabajo y la producción. 3. Marcan la diferencia y la especificidad, para situarse en la relación con otras diferencias y otras especificidades.

Sanz, Molina \& Soria (2007) realizaron un estudio titulado "Valoración del paisaje en el oasis del Valle de Uco (Mendoza, Argentina)" plantea que la calidad del paisaje constituye un recurso territorial que arraiga a las poblaciones en sus territorios. Esa calidad se aprecia, en un medio rural y urbano, fundamentalmente en su valor productivo, al que se 
vincula el trabajo, la ocupación de la población. Así mismo, enfatiza que la calidad del paisaje se vincula también a los valores identitarios, como la existencia de una conciencia muy desarrollada de pertenencia al territorio, de autosuficiencia; un entendimiento de la vida en el que cobran gran importancia las relaciones sociales, familiares, interfamiliares y entre amigos. Los elementos icónicos del paisaje.

Zapiain (2011) realizó una investigación sobre "La construcción colectiva de Lugar. Caso de estudio de la Vega de Granada", plantea la necesidad de analizar las nociones de «territorio» y «paisaje» desde su dimensión identitaria, como conceptos tremendamente complejos y donde los habitantes plasman sus anhelos, preocupaciones y amores. Así mismo, confirma la existencia de un vínculo real entre los sujetos sociales, la identidad y su paisaje-territorio.

Por otro lado, el estudio señala que los procesos de difusión urbana, y la subsiguiente propagación de la influencia socioeconómica y cultural de la ciudad, pueden afectar de forma drástica a la estructura física y social, cuyas consecuencias podría ser la pérdida de los usos, funciones y significados asociados tradicionalmente a su territorio, originando un proceso de desterritorización. Es decir, que se ocasiona la ruptura con los sistemas de explotación y asentamientos tradicionales además de poner en crisis los modelos de vida tradicional y, con ello, una importante proporción de la población comienzan a renunciar a una serie de prácticas productivas, sociales y culturales a partir de las cuales tradicionalmente habían configurado la territorización específica de su lugar.

Argentina (2014) desarrolló un estudio sobre identidad territorial, cuya investigación hace referencia en primer lugar que la identidad es considerada como dada, eterna e inmutable, pero poco visibilizada como dimensión clave de la construcción comunitaria. La efectividad del plan o programa de desarrollo contribuye a que los miembros de una comunidad tomen consciencia de la propia historia cultural. En segundo lugar, la transformación identitaria de las comunidades (a distintas escalas) se vincula con un empoderamiento resultante de la visibilización de un relato de una historia y geografía local armónica y sin conflictos.

Moraga (2009) en su investigación titulada "Geografía cultural e identidad territorial: caso de la comunidad de Cabuya, distrito de Cóbano, Puntarenas" plantea la necesidad de tomar en cuenta los rasgos de identidad territorial de las comunidades con miras a una mejor gestión y uso del espacio local para el desarrollo de actividades productivas, dado que dentro de un contexto socio-espacial, los habitantes cuentan con recursos, a los cuales se les puede dar un valor agregado y que a la vez sean aprovechados de forma sostenible. Así mismo, resalta la importancia de la gestión municipal, la articulación y coordinación de los actores sociales en la planificación local que sostenga el uso óptimo y adecuado de los recursos.

León (2014), realizó una investigación que se tituló "identidad territorial como contribución a los procesos de gobernanza territorial. Un análisis del contexto socio institucional en la zona del Macizo Peñas Blancas, Nicaragua", plantea que la gobernanza se tiene que considerar como la articulación de diferentes procesos de coordinación de actores: grupos sociales, instituciones, entre otros, que busquen congeniar metas conjuntas y definidas colectivamente que busque desde la concertación de actores hasta la resolución/ prevención de conflictos, siendo la integración del sector público, social y privado de manera territorial como una forma de generar espacios de encuentro y coordinación, con un enfoque inclusivo donde se facilite la participación e inclusión de los actores sociales.

En cuanto a la aproximación teórica sobre la identidad territorial y desarrollo local, se enfatiza los siguientes planteamientos: 


\section{Identidad Territorial}

La noción de identidad, entendido como una identidad territorial, aparece de la asociación entre el crecimiento y desarrollo de la comunidad con el aspecto geográfico. "De esta relación nace un producto que se construye en base a las experiencias de la población con las posibilidades y oportunidades que le brinda su territorio de asentamiento. Este producto es la Identidad. Es decir, la identificación de una determinada población con su espacio determinado" (ROZAS, 1997). Se encuentran dos grandes corrientes para comprender el concepto identidad:

En primer lugar, es la corriente esencialista, la cual ve la identidad como un rasgo natural de un grupo, recurre a la tradición supuestamente de tiempos inmemoriales, para fijar ciertos atributos como la religión, costumbres, creencias, etc. En segundo lugar, es la constructivista, donde la conciencia de otro pareciera determinante para establecer y construir la conciencia de un nosotros. Esta postura señala que las identidades son “dinámicas, interdependientes y cambiantes". Las identidades son entendidas como procesos cambiantes producto de la construcción permanente. Estas pasan por un proceso de metamorfosis. Parte de lo antiguo es recuperado y al mismo tiempo transformado. Es por ello que nunca se puede afirmar la existencia de una identidad social, siempre la identidad es un proyecto (Bengoa, 2002).

Para Mier (1988), la identidad es identidad cultural, la cual "se desarrollará, así como una ideología unificadora del grupo social frente a otros. De esta manera la lengua, la tradición histórica, la raza, el territorio y otros adquieren el carácter de símbolos distintivos de la identidad y se convierten en valores sociales cuya reproducción se propicia y se defiende" (Soto 1990: 30).

Según Thierry (1994), la identidad cultural encierra un sentido de pertenencia a un grupo social con el cual se comparten rasgos culturales, como costumbres, valores y creencias. La identidad no es un concepto fijo, sino que se recrea individual y colectivamente y se alimenta continuamente de la influencia exterior.

De acuerdo con estudios antropológicos y sociológicos, la identidad surge por oposición y como reafirmación frente al otro. Aunque el concepto de identidad trascienda las fronteras (como en el caso de los migrantes), el origen de este concepto se encuentra frecuentemente vinculado a un territorio.

En relación a lo anterior, la UNESCO señala que "La identidad sólo es posible y puede manifestarse a partir del patrimonio cultural, que existe de antemano y su existencia es independiente de su reconocimiento o valoración. Es la sociedad la que a manera de agente activo, configura su patrimonio cultural al establecer e identificar aquellos elementos que desea valorar y que asume como propios y los que, de manera natural, se van convirtiendo en el referente de identidad (...) Esta identidad involucra, por lo tanto, a las personas o grupos de personas que se reconocen históricamente en su propio entorno físico y social y es ese constante reconocimiento el que le da carácter activo a la identidad cultural (...)”. (UNESCO - PNUD 2005: 62) Al referirse a este concepto hacia colectividades o grupos ligados a un territorio, se deduce que esta identidad alcanza también distintas escalas y alcances territoriales, donde se diferencia dentro del mismo concepto, la identidad local de la regional, nacional, municipal, etc. De esta forma, es posible distinguir y especificardentro de una misma concepción deidentidad un "soy nicaragüense", "soy matagalpino", "soy tipitapeño", que denotan una identificación particular dentro de la noción de territorio o espacio cuyos límites (político-administrativos) son preestablecidos, y dan cuenta tácitamente de características psicosociales de la persona, así como características geográficas como el relieve y clima de su ambiente.

Por otra parte, es posible diferenciar entre aquellas identidades que, si bien dan cuenta de pertenencia a un territorio particular, éste trasciende de los límites físicos o administrativos, para dar cuenta de características 
más bien transversales (cosmovisión, espiritualidad, caracteres, modos de vida) a todo aquél que se identifique como tal:" soy costeña", "soy bocaneña", "soy pinolero".

De igual modo, el geógrafo polaco Dembicz (1991) desde el enfoque de la Geográfica Cultural manifiesta que "una de las referencias básicas para el ser humano es el lugar, su lugar y el espacio como un contexto más amplio del mismo. No sólo la pregunta: ¿de dónde eres? respalda a eso. También la de ¿quién eres? lleva de cierta manera tácita la cuestión del lugar. Un lugar y un espacio en la Tierra con los cuales uno se identifica, gustosa o penosamente".

En diferentes ámbitos de las ciencias sociales, la definición de concepciones como comunidad, se concibe en referencia a sus características territoriales. Así, el concepto de lo local tanto como el de comunidad hacen referencia también al espacio geográfico, ya que es el territorio el que registra los aspectos más permanentes de la personalidad individual y colectiva. De este modo, la concepción de Territorio desde el punto de vista de la geografía cultural viene a ser una interfase entre la sociedad y el ambiente, factores manifestados en una identidad colectiva que concibe el territorio como un espacio hecho propio por quienes las fundan (Goncalves, 2001).

La identidad, también se puede estudiar desde la Geografía de la Percepción, que nació a partir de los años 60 del siglo XX. Esta se adentra en el mundo subjetivo de las personas y en las imágenes mentales que los individuos tienen sobre el espacio que viven, iniciando una etapa de "revolución del comportamiento". El "behaviorismo" o conductismo, escuela psicológica de Estados Unidos, le facilitó a la Geografía el estudio personal de los seres humanos. Esta vertiente de la Geografía comienza con trabajos de Boulding (1956) ante la protesta de los esquemas de modelos económicos en la Geografía cuantitativa, en donde aparece el hombre y todas sus acciones racionalmente distribuidas en el espacio siguiendo unos criterios económicos (Homo Economicus). Ahora se trata de ir más allá, de tratar de entender al individuo, de interpretar su propia realidad y de intervenir según sus necesidades a fin de mejorar su calidad de vida (Millán, 2004).

Para Santos (1990), "este enfoque se basa en que cada individuo tiene una manera concreta de conocer el espacio, así como de evaluarlo [...]. Este espacio social está definido por los lugares que le son familiares y por las parcelas de territorio que debe recorrer entre esos diferentes lugares". Además, añade que "esta tendencia representa, en cierta forma, una ruptura con el economicismo y una forma de restitución de los valores individuales".

Cada individuo o grupo social tiene una apreciación sesgada de la realidad objetiva, ya que esta realidad se ve condicionada por sus valores culturales, sus experiencias, sus aspiraciones, es decir, una serie de características que conducen al ser humano a crear su propio universo que se organiza concéntricamente sobre él y que tiene un espacio inmediato que es el medio donde habita, espacio con una información personal y directa.

Vara (2008), señala que la geografía de la percepción emplea como instrumento metodológico los mapas mentales, es decir, croquis dibujados espontáneamente por el individuo sobre un determinado espacio, cargados de subjetividad. Estos mapas contienen su experiencia sensorial actual y experiencias pasadas que conectan lugares ya habitados anteriormente por él con el presente, obteniendo con ello una utilidad práctica (orientación) y algunas utilidades de orden psicológico, pudiendo desarrollar en el individuo una seguridad afectiva dentro de la sociedad en que habita. De esta manera, los mapas mentales son fundamentales porque ofrecen de cada individuo su visión particular del medio, características que difieren según la edad, hombre o mujer, destreza para dibujar, cultura y experiencia y conocimiento del medio. 


\section{Elementos de identidad territorial}

La identidad territorial expresa que la identidad cultural refleja la vida de la comunidad, su historia, patrimonio y territorio. Su preservación ayuda a reconstruir comunidades desmembradas, a restablecer su identidad, a crear un vínculo con su pasado y a crear un vínculo entre el pasado, el presente y el futuro. Para su estudio es importante tener en cuenta los siguientes elementos:

1. La geografía física del espacio en común caracterizado en términos hidrogeomorfológico, donde la localidad comparte las mismas características de suelo, clima, lluvia y paisajes, lo que desde ya marca una orientación productiva similar.

2. La historia, el territorio está marcado por la conquista y colonia del país, por ello están presentes un sin número de tradiciones culturales heredadas de generación en generación como, por ejemplo, las fiestas patronales.

3. La cultura, conformada por el trabajo de los hombres y mujeres en un espacio e historia común, que se plasma en la religiosidad, en la mantención de las tradiciones, elementos que se ven amenazados por el desarrollo de la modernidad.

4. El desarrollo productivo que es generado de los elementos anteriores y está dado por una zona de similares características, la economía del territorio.

5. Los seres humanos, los habitantes que viven en el territorio, que es la síntesis de todos los elementos señalados anteriormente, en ellos se conjuga el paisaje, la historia, la cultura tradicional, y el sentido productivo. Es posible establecer una identificación de lo propio y la autodefinición del territorio.

6. La asociatividad, que se refiere a las formas de asociatividad, la cual se construyen en base a una identidad común o compartida, que puede o no estar vinculada a un territorio o espacio común. El perfil de la asociatividad cambia al considerar localidades específicas dentro de cada comuna.
Allí emerge lo no registrado en el nivel comunal, "siendo lo numéricamente más significativo las pandillas juveniles, iglesias no católicas y clubes deportivos". La pertenencia asociativa representa un elemento básico en la construcción de capital social.

La asociatividad de las personas vinculadas a un territorio, nos orienta hacia otro concepto fundamental a la hora de hablar de identidades, es el concepto de comunidad, definido este como el conjunto de personas de un pueblo, región o nación, vinculadas por características o intereses comunes. (Real Academia de la Lengua Española)

\section{Desarrollo local}

Los objetivos básicos de toda sociedad, apuntan a lograr un desarrollo común para todos sus miembros, en sus diversas dimensiones. Conceptualmente, el término desarrollo es definido en su acepción económica como "la evolución progresiva de una economía hacia mejores niveles de vida", acepción que parece ser la más arraigada entre las altas esferas de poder y la más difundida por los gobiernos locales. Sin embargo, y según diversos autores, el desarrollo debe ser entendido como un medio y no como un fin. Es así como Boisier (2003), alejándose del dogma desarrollista, puntualiza que el desarrollo es "el logro de un contexto, medio, situación, entorno o como quiera llamarse, que facilite la potenciación del ser humano para auto transformarse en persona humana, en su doble dimensión: biológica y espiritual, capaz en esta última condición de conocer y amar".

El desarrollo local se ve desde varios enfoques, en este caso será entendido desde el desarrollo endógeno, el que se crea desde la base, desde abajo hacia arriba, dado que responde dentro de un contexto de cambios en la innovación tecnológica, del desarrollo de las comunicaciones, esta su vez, creando condiciones objetivas y subjetivas que obligan a repensar el papel que los factores endógenos pueden desempeñar en 
cada territorio. Se produce cambios de paradigmas para interpretar el desarrollo de los territorios, el desarrollo de abajo hacia arriba. (Alonso Alemán \& Bell Heredia, 2013)

El desarrollo local endógeno es una teoría que propone un mecanismo de acumulación especifico, basado en una lógica de organización, un sistema de aprendizajes y una fuerte integración territorial, que apuesta por mantener una dinámica propia, así como por otorgar a las comunidades locales un instrumento para la acción. Se comprende como una estrategia que persigue satisfacer las necesidades y demandas de una población local, mediante la participación activa de la población en los procesos de crecimiento para el desarrollo. Los habitantes del territorio participan como actores fundamentales del proceso de cambio.

Lazo et al. (2007), plantea que el desarrollo local es un proceso activador de la economía y dinamizador de la sociedad, que mediante el aprovechamiento de los recursos existentes en un determinado territorio, se pone en capacidad de estimular y fomentar el desarrollo económico y social, garantizando la sostenibilidad de los procesos, creando empleo, riquezas, y poniendo está en función de mejorar la calidad de vida y la satisfacción de las necesidades siempre crecientes de las comunidades locales.

A partir del estudio de la problemática de desarrollo local se identifican, al menos, cuatro dimensiones de este proceso: económica, caracterizada por un sistema específico de producción donde los empresarios locales usan, de forma eficiente, los factores productivos con el objetivo de alcanzar niveles de productividad que les permita ser competitivos en los mercados; sociocultural, en la que los actores económicos y sociales se integran a las instituciones locales formando un sistema de relaciones que incorporan los valores de la sociedad en el proceso de desarrollo; política, que se instrumenta a través de iniciativas locales para crear un entorno local que estimula la producción y favorece el desarrollo; ambiental, dado que todo lo anterior debe funcionar sobre la base del tratamiento adecuado de los recursos naturales. (Rodríguez et al., 2001)

El desarrollo local en esta investigación se reubica en un marco constructivista, subjetivo, valorativo y por cierto, endógeno, o sea, directamente dependiente de la autoconfianza colectiva en la capacidad para "inventar" recursos, movilizar los ya existentes y actuar en forma cooperativa y solidaria desde el propio territorio, generándose una proalimentación de compensación. En tanto proceso y resultado intangible, el desarrollo es una matriz causal que no puede tener sino la misma dimensión: la intangibilidad, y por tanto, será inútil asociarlo con meros avances materiales. Dado que el propósito central de toda propuesta de desarrollo no puede ser otro sino "otorgarles a los seres humanos su dignidad como personas, en un marco de valores en el cual la libertad, la democracia, la justicia, la ética, la estética, la solidaridad y la variedad constituyen sus elementos definitorios. (Boisier, 2003)

Por consiguiente, este enfoque de desarrollo supone ubicar a los seres humanos en un tejido social que se debe de densificar y articular hasta que se transforme en una verdadera comunidad, es decir, en una asociación de personas que basan su asociatividad en la "razón natural", esto es, en la emocionalidad y en un sentido de pertenencia. Se debe crear una comunidad con un fuerte sentido de identidad. Por otro lado, se tiene que tener en cuenta el carácter subjetivo del desarrollo, resulta prescindible cuantificar, potenciar y articular los diversos capitales intangibles que genera el desarrollo. Debiendo ser ejecutado todo este operativo del desarrollo, de forma endógena.

Gallicchio (2004) señala que el desarrollo local es una estrategia para alcanzar el desarrollo, no un paradigma. Corresponde a un proceso orientado que surge como una ruta diferente y alternativa de desarrollo nacional y regional, constituyendo una nueva manera de comprender y construir cada país. En términos generales, este autor conceptualiza el desarrollo local como "un proceso de concertación entre los agentes- 
sectores y fuerzas que interactúan en un territorio determinado, para impulsar, con la participación permanente, creadora y responsable de ciudadanos y ciudadanas, un proyecto común de desarrollo que implica la generación de crecimiento económico, equidad, cambio social y cultural, sustentabilidad ecológica, enfoque de género, calidad y equilibrio espacial y territorial con el fin de:

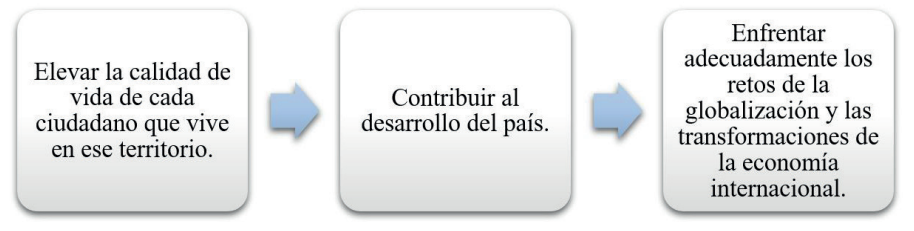

En otras palabras, el desarrollo local es un proceso mucho más sociopolítico que económico. Los desafíos son mucho más de articulación de actores y capital social que de gestión local

Ilustración 2. Desarrollo territorial endógeno (Boisier, 2003)

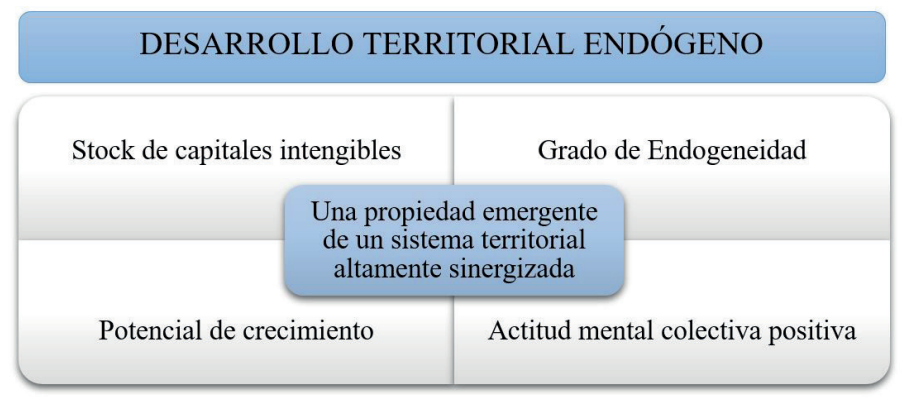

Por otro lado, es un requerimiento fundamental del desarrollo local, la presencia activa de una identidad cultural local capaz de manifestar sus acciones e inquietudes. Al respecto, Valenzuela (2003) señala que "una de las piedras angulares de un proceso de desarrollo local es el fortalecimiento de la identidad y la cultura local. El dinamismo, la creatividad y la energía que nutren el desarrollo local provienen de un nuevo sentimiento de pertenencia de los ciudadanos respecto de su localidad. La afirmación de un sentir colectivo de autoestima que fortalece la identidad local, permite a los ciudadanos relacionarse entre sí y con otras localidades en un espíritu de mayor armonía, con un nuevo sentido de confianza y seguridad. El desarrollo local comienza a partir de la afirmación de quiénes somos, de dónde venimos, a qué pertenecemos y qué nos distingue".

Un aspecto importante que no se debe de omitir en el tema de desarrollo local es la modernización, cabe destacar que existe una diferencia conceptual entre los términos concernientes a la modernidad, de este modo el concepto modernidad se presenta como una etapa histórica; modernización como proceso socioeconómico que trata de ir construyendo la modernidad, y modernismo como proyectos culturales que renuevan las prácticas simbólicas con un sentido experimental o crítico.

Acorde con Rozas (1997), la modernización surge como un fenómeno desestabilizador en la construcción de la identidad, generando impactos en el eje social, alterando las dinámicas de transformación social, cultural, la concepción y el sentido de pertenencia hacia el territorio.

Boisier (1996) hace referencia a los conflictos entre la modernidad y el territorio desde un análisis regional. $\mathrm{Su}$ perspectiva propone un punto de vista más beneficioso de esta relación, en términos económicos, donde la cultura y la identidad asociadas al territorio hoy se revitalizan, no sólo como valores intrínsecos, sino como factores de competitividad regional.

Por otro lado, Enríquez (2003) indica que “el Desarrollo Local es un proceso de concertación entre los agentes (sectores y fuerzas) que interactúan en un territorio determinado para impulsar, con la participación permanente, creadora y responsable de ciudadanos y ciudadanas, un proyecto común de desarrollo, que implica la generación de crecimiento económico, equidad, cambio social y cultural, sustentabilidad ecológica, enfoque de género, calidad y equilibrio espacial y territorial; su fin es elevar la calidad de vida de cada familia, ciudadano y ciudadana, residente en ese territorio, contribuir al desarrollo del país y enfrentar, 
de forma adecuada, los retos de la globalización y las transformaciones de la economía mundial".

La fundación CARE Internacional (1998), define el desarrollo local como un "proceso participativo que tiene como objetivo mejorar la calidad de vida y el bienestar de la población. Este proceso implica generar $\mathrm{y}$ fortalecer las capacidades y ampliar las oportunidades económicas enfocadas al municipio pero vinculadas al desarrollo nacional"'.

Otro concepto de Desarrollo Local señala que éste es "un proyecto común que incorpora y combina el crecimiento económico, la equidad, la mejora sociocultural, la sustentabilidad ambiental, la igualdad de géneros, la calidad y equilibrio espacial, sustentado por un proceso de democracia participativa y concertación de los diversos agentes de un territorio, con el objetivo de elevar la calidad de vida de las personas y las familias de dicho territorio apropiación de la cultura y otras formas de comportamiento humano al introducirse con fuerza el concepto de sociedad y estilo de vida basado en el mundo occidental moderno, muy distinto al de las culturas que no comparten los mismos parámetros sociales" ${ }^{2}$

\section{El término local resurge en el desarrollo}

La globalización ha reestructurado el orden de lo local, reconsiderar las dimensiones de los espacios locales y en última instancia fortalece un concepto que parecía disolverse en un futuro globalizado. García Canclini precisa la globalización como "un proceso de fraccionamiento articulado del mundo y recomposición de sus pedazos", en esa medida no es un proceso de homogenización de las diferencias y desaparición de la diversidad, sino un reordenamiento de ellas (Arellano $\&$ Cerpas, 2004).

1 Red de Intercambio de Desarrollo Local (1998), El Desarrollo Local y Regional en el Desarrollo Nacional: Una Propuesta a la Nación, Pág. 5. 2 www.care.org.sv
La globalización no sólo opera como homogenizadora e integradora de culturas, sino que también genera estratificación, segregación, exclusión y diferenciación. En este sentido "opera no tanto para borrar las diferencias sino para reordenarlas, con el fin de producir nuevas fronteras menos ligadas a los territorios que a la distribución desigual de los bienes de mercado".

De acuerdo con López (1991: 42) "Cuando se habla de lo local, se refiere a un espacio, a una superficie territorial de dimensiones razonables para el desarrollo de la vida, con una identidad que lo distingue de otros espacios y de otros territorios y en el cual las personas realizan su vida cotidiana: habitan, se relacionan, trabajan, comparten normas, valores, costumbres, representaciones simbólicas".

Por otro lado, Boisier (1996) señala que "Si en algún momento la ilusión de la modernidad albergó la idea de que era posible crear al ciudadano del mundo, libre de atávicos lazos territoriales (carente de lazos de identidad territorial), hay que convenir que la crisis de la racionalidad moderna, echó por tierra tal creencia. Hoy día por el contrario se percibe un movimiento de vuelta al Territorio". Como se aprecia el autor menciona que el derrumbe del Estado benefactor y de las redes sociales de apoyo (gran empresa, fuerte sindicato, empleo estable y seguridad social colectiva) vino a fortalecer el ámbito local como un nuevo territorio de solidaridad. Este territorio solidario da paso a la asociatividad de individuos que, ante la amenaza o acecho de algún peligro sienten la necesidad de agruparse y solidarizar entre ellos mismos.

Este sentimiento de retorno a lo local, de sentirse reconocido localmente también es descrito por autores como Vega (1991), manifestando que "El mundo se universaliza en lo económico, pero a la vez, las identidades se empequeñecen, nacen expresiones nacionales, o sea "ante la incertidumbre de universalizarme, yo me aseguro retornando a lo comunal, a lo local..." 
En síntesis, la escala local, es decir las localidades, surgen como las nuevas unidades de trabajo para el logro de los proyectos de desarrollo. Este nuevo contexto territorial es mucho más manejable desde el punto de vista estratégico, pero del mismo modo, fuertemente complejo en sus redes articulares y en sus procesos de construcción de identidad, se levanta hoy en día como la base de toda estructura de planificación territorial, pensando en la ventaja de trabajar a escala local los problemas globales del territorio. Sin que, por esto, la influencia que ejercen dichos territorios intervenidos sea proporcional a su dimensión.

\section{Elementos del desarrollo local}

De acuerdo con Gutiérrez (2006: 64) el desarrollo local es el proceso socio ambiental -territorial que debe ser pensado, planeado, promovido y gestionado, con el objetivo de alcanzar las siguientes metas:

Ilustración 3. Alcances del desarrollo local porpuesto por Gutiérrez (2006)

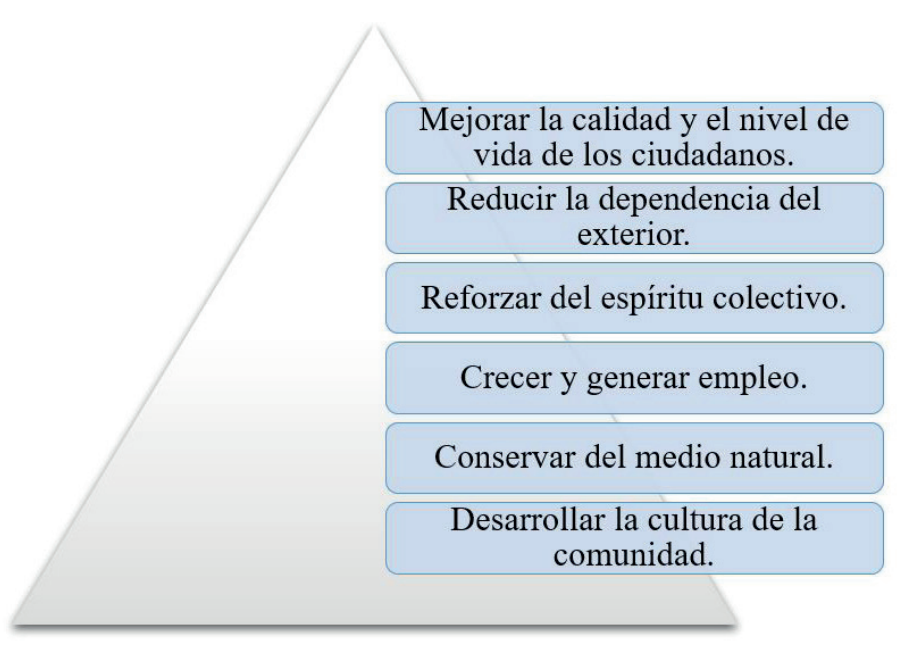

Los actores locales: Protagonismo y su identificación

Las teorías de la acción han adquirido cierto protagonismo en la mayoría de las ciencias sociales durante los últimos años, y la Geografía no resulta una excepción. Frente a una visión que intentaba explicar la organización y dinamismo de los territorios o la distribución de los diversos elementos que los componen mediante la referencia a todo un conjunto de factores explicativos, este tipo de enfoques centra la atención sobre la existencia de individuos y organizaciones que, a partir de la toma de decisiones, ejercen un efecto determinante sobre la construcción y destrucción de las realidades socio espaciales que interesan a los geógrafos. Identificar qué actores operan en un territorio concreto, conocer y comprender sus características o estructura interna, intereses y valores, los mecanismos que guían el proceso decisional, las estrategias que aplican para alcanzar sus objetivos o sus posibles interacciones (colaboración, competencia, conflicto) son aspectos a los que ahora se concede una destacada atención. (Martínez, 2010)

Por otro lado, en el enfoque del desarrollo local las relaciones entre Estado y sociedad ocupan un lugar destacado en la medida que este proceso es producto de las acciones de todos los actores involucrados en un entramado que incluye tanto a los niveles del Estado como a los actores económicos, sociales y políticos. En efecto, el desarrollo local postula que la orientación de cada proyecto de desarrollo, y la estructura de sectores y actores que involucra, constituyen configuraciones específicas de cada experiencia y su formulación es resultado de un proceso político de debate de los actores del territorio.

En esta línea, Cavestany (2000) apunta que "el desarrollo no es sólo un proceso económico, sino ante todo un proceso político, de acción concertada de actores públicos y privados -económicos, sociales, políticos, tecnológicos-, que operan y toman decisiones en el territorio, o que inciden en él'. La acción colectiva en el territorio cobra una importancia fundamental puesto que da cuenta de la existencia de una sociedad local que constituye la base social del proceso.

Así que la clave del desarrollo radica en la articulación provechosa de los recursos y las capacidades locales, potencial que se denomina capital sinergético: "la capacidad social de promover acciones de conjunto 
dirigido a fines colectiva y democráticamente aceptados, con el fin de obtener un resultado donde el producto final sea mayor que la suma de las partes" (Boisier, 2000:280)

\section{Actores del desarrollo local}

El desarrollo local es un proceso que implica la concertación de actores que se relacionan dentro de los límites de un territorio determinado, por lo tanto, es necesario conocer quiénes son dichos actores y el papel que deben desempeñar para la consecución de los objetivos de desarrollo. A continuación, se muestran los derechos y competencias que poseen cada uno de los actores a partir de lo establecido en la Ley de Municipios de Nicaragua. (Alvarado \& Rivas, 2004)

1. El gobierno municipal. Es el responsable de la mayor parte de las actividades del proceso de desarrollo local. Es uno de los actores locales, dentro del cual adquieren relevancia los funcionarios responsables de planear, implementar, gestionar y evaluar las políticas territoriales. El modelo clásico general del perfil de estos funcionarios caracteriza su capacidad de "buen administrador", esto es, que posee la capacidad de administrar eficientemente los recursos del municipio. Así mismo, se espera que tiendan a poseer suficiente capacidad como para obtener recursos de los otros niveles del Estado para las políticas municipales. (Rofman \& Villar, 2005)

2. Así que los funcionarios municipales tienden a reconvertirse hacia un perfil de facilitadores, catalizadores y mediadores de los intereses de los actores de la comunidad, que no siempre son coincidentes entre sí. En efecto, armonizar y conducir políticamente intereses de los distintos actores es la nueva tarea de los políticos locales, lo que supone una relación más dinámica con los actores locales. Al perfil del funcionario tradicional que se encargaba de administrar con eficiencia, obtener y asignar recursos; ahora se agrega la de liderar proyectos innovadores en dónde debe superar bloqueos, canalizar y diluir los conflictos, en fin, articular con los actores locales.

3. Las Comunidades. La participación es un derecho de la comunidad a intervenir en las decisiones que le afectan, y es un elemento esencial para la democracia. La participación es también un deber de la comunidad, debido a que sus problemas no los puede solucionar el Estado por más que éste haya adoptado una serie de funciones y tareas, y por tanto, muchas de ellas pueden ser absorbidas y ejercida por la ciudadanía. (Enriquez, 2003)

4. El Gobierno Central. Este debe convertirse en el principal promotor del Desarrollo Local, ya que constitucionalmente se establece que el Estado está organizado para la consecución del bien común, y es obligación de éste asegurar a sus habitantes el goce de la libertad, la salud, la cultura, el bienestar económico y la justicia social. Por otra parte, se establece que las instituciones del Estado deberán colaborar con la municipalidad en el desarrollo de los planes Municipales, además de regular y garantizar el desarrollo y la autonomía de los Municipios. (Enriquez, 2003)

5. Las instancias de apoyo. Se refiere a las entidades o grupos que trabajan en pro del desarrollo local y que no son beneficiarios directos en las acciones de los programas de desarrollo. Estos son principalmente:
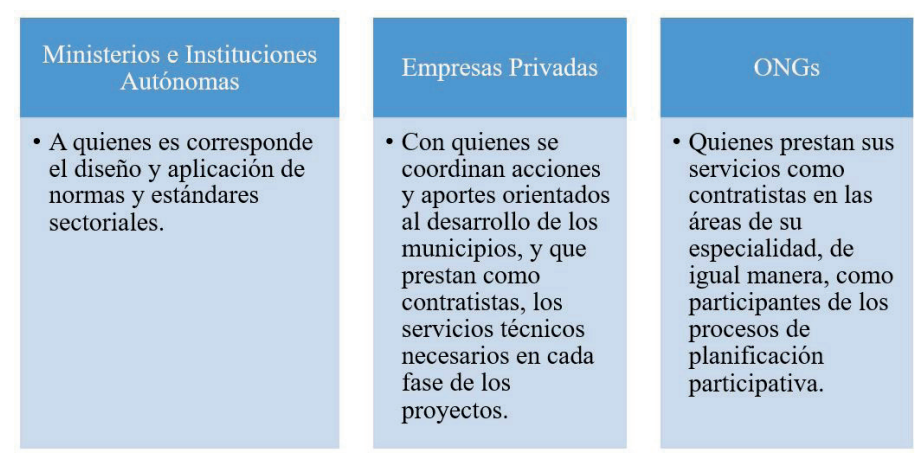
Para Enriquez (2003) las definiciones anteriores de desarrollo local, proponen algunos componentes en común:

- Desarrollo sostenible y bienestar de la población que busca un desarrollo en los planos económico, social y ambiental, tanto a nivel nacional como municipal, de forma tal que no se comprometa el desarrollo de las futuras generaciones y esté orientado a mejorar la calidad de vida de la población.

- Desarrollo local y territorial como parte indispensable del desarrollo territorial que reconoce al municipio como unidad básica del Estado, por lo que no puede haber desarrollo local sin un desarrollo municipal. En esto es importante destacar dos elementos: el municipio como conjunto de ciudadanos, que comparten un territorio; y la municipalidad como aparato político administrativo de gobierno.

- Equidad y género que busca la generación de oportunidades de participación ciudadana en el desarrollo económico, social y cultural de los municipios, tanto de hombres como de mujeres en las actividades de se emprendan en el municipio.

- Pertenencia e inclusión social que reconoce el sentido de pertenencia y arraigo a una localidad como elemento integrador y regulador de la sociedad. La identificación con una localidad y una comunidad se convierte en un elemento poderoso de inclusión social, de seguridad ciudadana y de desarrollo, y además permite reconocer la riqueza de la diversidad de los aspectos culturales y sociales de los municipios.

- Desarrollo de las capacidades locales que busca la generación y fortalecimiento de las capacidades surgidas a nivel local, que hagan autónomo y sostenible el desarrollo a mediano y largo plazo.

- Participación ciudadana que fortalece la participación de los habitantes a nivel local y aumenta la incidencia de los intereses locales en los órganos del gobierno, por lo que requiere una nueva cultura cívica, donde la participación permita exigir derechos, pero también compartir responsabilidades. Al potenciar la participación ciudadana se busca establecer una forma adecuada de relación entre las autoridades municipales y la población, que le permita a esta última incidir en la gestión municipal.

- Concertación entre actores que fomenta la capacidad de concertar entre los distintos grupos sociales, haciendo sostenible a largo plazo los procesos socioeconómicos; de ahí que requiera del establecimiento de acuerdos para trabajar en función del interés común de los habitantes de las localidades. Por esta razón, el desarrollo local contribuye a sentar las bases de la gobernabilidad local.

El desarrollo local es un proceso necesario para optimizar las condiciones y calidad de vida de la población, a través de la generación de mayores y mejores oportunidades de empleo, del incremento del ingreso, del acceso a servicios básicos y en armonía con el ambiente.

\section{CONCLUSIONES Y/O RECOMENDACIONES}

En conclusión, la revisión bibliográfica presenta estudios relacionados con la "identidad territorial y desarrollo local en la zona norte de la ciudad de Tipitapa, municipio de Tipitapa, departamento de Managua 2017-2019". Estos se han desarrollado a nivel internacional y nacional. En síntesis, las investigaciones mencionadas en el acápite anterior señalan la identidad territorial como una herramienta importante para determinar el sentido de pertenencia de la población con su espacio, ambiente y el uso de los recursos naturales. Así mismo, consideran que en el contexto social, económico e institucional es una pieza relevante para discutir y analizar estrategias de cogestión adaptativas, considerando a los actores claves, buscando generar líneas de trabajo acorde a los intereses comunes, promoviendo la coordinación entre organizaciones públicas, privadas y la ciudadanía e incorporando los factores externos al territorio, 
se podrán generar respuestas sostenibles para la gobernanza y gestión participativa e inclusiva.

En cuanto a los planteamientos teóricos, los distintos autores hacen hincapié en la conceptualización del término de identidad territorial y los elementos que la constituyen, así mismo se plantea la definición de desarrollo local, que en el caso del estudio se enfatizará en el desarrollo enmarcado en una concepción constructivista, subjetivo, valorativo y endógeno, es decir, directamente dependiente de la autoconfianza colectiva en la capacidad para "inventar" recursos, movilizar los ya existentes y actuar en forma cooperativa y solidaria desde el propio territorio, generándose una proalimentación de compensación.

Por otro lado, se destaca el papel protagonista de los actores sociales en el desarrollo local, el apoyo y articulación que debe de existir entre ellos para optimizar los recursos humanos que poseen los territorios. Es importante subrayar que se necesita conocer el sentido de pertenencia de la población con su espacio y las condiciones de desarrollo de los habitantes para obtener una comprensión de la realidad a estudiar. Otro punto que consideran el artículo es la importancia del estudio de la identidad territorial, como una base para el desarrollo local, además es se puede convertir en una herramienta metodológica en la planificación territorial que fomente la identidad con su espacio y recursos naturales por parte de las autoridades municipales, organismos presentes en los territorios y por supuesto los habitantes. En fin, se constató que existen antecedentes y teoría que fundamentan el tema de estudio.

Para enriquecer aún más los antecedentes y marco teórico de la investigación sobre identidad territorial y desarrollo local se recomienda continuar con la revisión bibliográfica y el análisis documental, dado que permitirá conocer más aportes teóricos relacionados con el tema.

\section{REFERENCIAS BIBLIOGRÁFICAS}

Alonso Alemán, A. M., \& Bell Heredia, R. E. (2013). Desarrollo Territorial a escala local. La Habana: Editorial UH.

Alvarado Zepeda, C. A., \& Rivas Gómez, L. E. (2004). Indicadores de Desarrollo Local: Una Clasificación de los Municipios del Departamento de Cuscatlán. San Salvador: UNIVERSIDAD DE EL SALVADOR.

Arellano Yévenes., C. (2007). Identidad territorial como base del desarrollo local en el secano interior de san javier de loncomilla, región del maule. Estudio de caso de la sociedad campesina barrancas y valle de pichamán. Santiago: Universidad de Chile.

Boiser, S. (1992). Teorías y Meáforas sobre desarrollo territorial. Santiago: CEPAL.

Boiser, S. (1996). Modernidad y Territorio. Santiago: Cuaderno de ILPES.

Boiser, S. (2001). Conversaciones Sociales y Desarrollo Regional: Potenciación del capital sinergético y creación de sinergia cognitiva en una región (región del Maule, Chile). Santiago: Editorial Universidad de Talca, Chile.

Boiser, S. (2003). El desarrollo en su lugar: El Territorio en la sociedad del conociemiento. Chile: Serie GeoLibros, PUC.

Enriquez, A. (2003). Desarrollo Local: hacia una nueva forma de desarrollo nacional y centroamericana, en alternativas para el desarrollo. El Salvador: FUNDE.

FAREM-Estelí. (8 de marzo de 2017). Revista Cientifica FAREM-Estelí. Obtenido de Revista Cientifica FAREM-Estelí: http://www.farem.unan. edu.ni/revistas/index.php/RCientifica/pages/view/ publicaci $\% \mathrm{C} 3 \% \mathrm{~B} 3 \mathrm{n}$

Grupo de Investigación I+C. (S.F). Identidad y conciencia regional en Murcia. Murcia: Universidad de Murcia.

Guirao Josep, O. A. (2008). El artículo de revisión. Revista iberoamericana de enfermería comunitaria, 5.

León Leiva, K. (2014). Identidad territorial como contribución a los procesos de gobernanza teritorial. 
Torrialba: CATIE.

Lorente Velasco, M. M. (2014). La pérdida de identidad ante el crecimiento urbanístico. Espacio y tiempo. Revista de Ciencias de la Educación, Artes y Humanidad, 10.

Molano, O. (2006). La identidad cultural, uno de los detonantes del desarrollo territorial. RIMISP.

Moraga López, G. (2009). Geografía cultural e identidad territorial: caso de la comunidad de Cabuya, distrito de Cóbano, Puntarenas. Heredia: UNIVERSIDAD NACIONAL “CAMPUS OMAR DENGO”.

Martínez Pérez, Y. (2010). Elementos sustanciales del desarrollo local. Revista OIDLES.

Ramírez Hernández, J. A., \& Fernández Christlieb, F. (2013). Paisaje e identidad en El Arbolito, Pachuca, Hidalgo. Jóvenes y adultos en apego a un barrio ex minero. Investigaciones Geográficas, Boletín del
Instituto de Geografía, UNAM, 73.

Rofman, A., \& Villar, A. (2005). Los actores del desarrollo local en el contexto en el cotexto argentino: orientaciones teóricas e instrumentos de análisis. 2-9.

Suárez Egizabal, M. (2003). Interrelación entre la identidad de barrio y la identidad personal. Un estudio a través de la memoria.

Valenzuela Rojas, C. (2014). Identidad barrial en zonas patrimoniales: el caso del barrio santa lucíamulato gil de castro-parque forestal. Santiago: UNIVERSIDAD ACADEMIA DE HUMANISMO CRISTIANO.

Van de Velde, H., \& Miranda Moreno, D. (2007). Desarrollo local. Un texto de referencia y consulta. Estelí: UNAN-Managua. 